\title{
Exopolysaccharide Produced by Probiotic Bacillus albus DM-15 Isolated From Ayurvedic Fermented Dasamoolarishta: Characterization, Antioxidant, and Anticancer Activities
}

\begin{abstract}
Annadurai Vinothkanna1,2, Ganesan Sathiyanarayanan ${ }^{3}$, Amit Kumar Rai , Krishnamurthy Mathivanan ${ }^{5}$, Kandasamy Saravanan ${ }^{6}$, Kumaresan Sudharsan $^{7}$, Palanisamy Kalimuthu ${ }^{7}$, Yongkun $\mathrm{Ma}^{1 *}$ and Soundarapandian Sekar ${ }^{2 \star}$
\end{abstract}

OPEN ACCESS

Edited by:

Obulisamy Parthiba Karthikeyan, University of Houston, United States

Reviewed by:

Margarita Kambourova, Bulgarian Academy of Sciences,

Bulgaria

Kandasamy Saravanakumar, Kangwon National University,

South Korea

*Correspondence: Yongkun Ma

mayongkun@ujs.edu.cn

Soundarapandian Sekar sekarbiotech@yahoo.com

Specialty section:

This article was submitted to

Microbiotechnology,

a section of the journal

Frontiers in Microbiology

Received: 09 December 2021

Accepted: 18 January 2022

Published: 03 March 2022

Citation: Vinothkanna $A$

Sathiyanarayanan G, Rai AK Mathivanan K, Saravanan K, Sudharsan K, Kalimuthu P, Ma Y and Sekar S (2022) Exopolysaccharide Produced by Probiotic Bacillus albus

DM-15 Isolated From Ayurvedic

Fermented Dasamoolarishta:

Characterization, Antioxidant, and Anticancer Activities.

Front. Microbiol. 13:832109. doi: 10.3389/fmicb.2022.832109
${ }^{1}$ School of Food and Biological Engineering, Jiangsu University, Zhenjiang, China, ${ }^{2}$ Department of Biotechnology, Bharathidasan University, Tiruchirappalli, India, ${ }^{3}$ Institute of Chemistry, University of Neuchâtel, Neuchâtel, Switzerland, ${ }^{4}$ Institute of Bioresources and Sustainable Development, Regional Centre, Gangtok, India, ${ }^{5}$ School of Minerals Processing and Bioengineering, Central South University, Hunan, China, ${ }^{6}$ Department of Biochemistry, Bharathidasan University, Tiruchirappalli, India, ${ }^{7}$ Department of Chemistry, The Gandhigram Rural Institute (Deemed to be University), Dindigul, India

An exopolysaccharide (EPS) was purified from the probiotic bacterium Bacillus albus DM-15, isolated from the Indian Ayurvedic traditional medicine Dasamoolarishta. Gas chromatography-mass spectrophotometry and nuclear magnetic resonance (NMR) analyses revealed the heteropolymeric nature of the purified EPS with monosaccharide units of glucose, galactose, xylose, and rhamnose. Size-exclusion chromatography had shown the molecular weight of the purified EPS as around $240 \mathrm{kDa}$. X-ray powder diffraction analysis confirmed the non-crystalline amorphous nature of the EPS. Furthermore, the purified EPS showed the maximum flocculation activity (72.80\%) with kaolin clay and emulsification activity (67.04\%) with xylene. In addition, the EPS exhibits significant antioxidant activities on DPPH (58.17 $\pm 0.054 \%)$, ABTS (70.47 $\pm 0.854 \%)$ and nitric oxide (58.92 $\pm 0.744 \%)$ radicals in a concentration-dependent way. Moreover, the EPS showed promising cytotoxic activity $\left(20 \pm 0.97 \mu \mathrm{g} \mathrm{mL}{ }^{-1}\right)$ against the lung carcinoma cells (A549), and subsequent cellular staining revealed apoptotic necrotic characters in damaged A549 cells. The EPS purified from the probiotic strain B. albus DM-15 can be further studied and exploited as a potential carbohydrate polymer in food, cosmetic, pharmaceutical, and biomedical applications.

Keywords: probiotics, Bacillus ablus, exopolysaccharides, characterization, antioxidant, anticancer potential

\section{INTRODUCTION}

Exopolysaccharides (EPSs) are structurally heterogeneous carbohydrate polymers produced by microorganisms (bacteria, yeast, fungi, and microalgae). Microorganisms produce EPSs in the presence of excess carbon sources or under extreme environmental conditions as a firmly associated cell-bound capsule or a loosely attached slime layer (Lynch et al., 2018; Andrew and Jayaraman, 2020). Bacterial EPSs are functionally involved in biofilm formation and environmental stress 
management to protect the bacterial cells from harsh conditions. EPSs also act as potential antigenic determinants in certain Gram-negative bacteria, i.e., Klebsiella pneumoniae capsular acidic polysaccharides ( $\mathrm{K}$ antigen), which provide solid support to the bacteria to combat the host immune systems (Ma et al., 2018; Andrew and Jayaraman, 2020). Bacterial EPSs are widely used in pharmaceutical, food, petroleum, and cosmetic industries as emulsions, thickening agents, surfactants, viscosifiers, flocculants, additives, and preservatives (Freitas et al., 2011; Lynch et al., 2018). In addition, some bacterial EPSs also possesses anti-inflammatory, antitumor, antioxidants, antibacterial, antiviral, cholesterol-lowering, prebiotic, and immunomodulatory activities (Freitas et al., 2011; Saadat et al., 2019; Park et al., 2022). At present, EPSs are commercially available in the market as xanthan, gellan, dextran, alginates, curdlan, acetan, succinoglycan, and hyaluronan, and these polymers are generally nontoxic to the environment, biocompatible, and completely biodegradable (Freitas et al., 2011; Andrew and Jayaraman, 2020; Daba et al., 2021).

The Indian traditional fermented medicines have treated various diseases for many centuries. Recent studies have demonstrated the diverse microbial communities, especially probiotic bacteria from the traditional fermented foods and polyherbal fermented traditional medicines, namely Arishta (fermented decoctions) and Asava (fermented infusions). Polyherbal formulations' composition and medicinal properties were extensively studied, and the fermentation processes were mainly mediated by self-generated microbial communities (Saadat et al., 2019; Sekar and Vinothkanna, 2019; Vinothkanna and Sekar, 2019). Different EPSs were purified from diverse bacteria, including probiotic bacterial strains isolated from traditional fermented foods and beverages ( $\mathrm{Hu}$ et al., 2019; You et al., 2020; Park et al., 2022). Our previous study also showed a novel EPS polymer from the Bacillus licheniformis AG-06 isolated from the Indian Ayurvedic polyherbal fermented traditional medicine (Vinothkanna et al., 2021). Hence, probiotic microorganisms from the Indian Ayurvedic polyherbal formulations can be further exploited to produce food-grade EPSs with medicinal properties. EPSs from probiotic bacteria had shown significant rheological, flocculation, emulsification, and pharmaceutical properties (i.e., anticancer and immunomodulation) (Insulkar et al., 2018; Ramamoorthy et al., 2018; Vinothkanna et al., 2021). However, EPSs purified from probiotic bacteria isolated from traditional fermented medicines are mostly unknown, and assessing their therapeutic potentials can lead to an exciting opportunity for nutraceutical applications.

Functional groups present in the EPSs are mainly responsible for many biological properties. For example, sulfate groups in the bacterial EPS are considered potential lead for the antiproliferative, anticoagulant, fibrinolytic, antimicrobial, prebiotic, and wound-healing properties (Haroun-Bouhedja et al., 2000; Ruiz-Ruiz et al., 2011; Almutairi and Helal, 2021). Sulfated exopolysaccharide purified from the Anoxybacillus gonensis YK25 showed significant anticancer activity against the lung cancer cells (Karadayi et al., 2021). In addition, sulfated
EPS (levan) derived from the Bacillus megaterium PFY-147 had shown free radical scavenging activity, antioxidant and probiotic activities, which validate the potential implications of sulfated EPS in biomedical applications (Pei et al., 2020). Therefore, exploring the sulfated EPSs from the probiotic bacteria isolated from the fermented medicine is essential to understand the role of EPSs in fermented medicines and their therapeutic interventions.

To meet all these challenges, we have systematically studied the EPS derived from the probiotic bacterium Bacillus albus DM-15 isolated from polyherbal fermented traditional medicine (Dasamoolarishta) of Indian Ayurveda. The purified EPS was characterized by various analytical methods, including two-dimensional nuclear magnetic resonance (NMR) spectroscopic analysis. Functional properties such as flocculation, emulsification and in vitro biological activities, including antioxidant and anticancer potential, were determined.

\section{MATERIALS AND METHODS}

\section{Chemicals and Reagents}

Trifluoroacetic acid (TFA), monosaccharide standards (glucose, galactose, rhamnose, mannose, xylose, and arabinose), deuterium oxide $\left(\mathrm{D}_{2} \mathrm{O}\right)$, L-ascorbic acid, 2-diphenyl-1-picrylhydrazyl (DPPH), 2, 2'-azino-bis 3-ethylbenzothiazoline-6-sulfonic acid (ABTS), 3-(4,5-dimethylthiazol-2-yl)-2,5-diphenyl-2Htetrazolium bromide (MTT), Acridine orange/ethidium bromide $(\mathrm{AO} / \mathrm{EB})$ and 4,6-diamidino-2-phenylindole (DAPI) were procured from Sigma-Aldrich (Bangalore, India). Further, sodium nitroprusside, benzene, n-Hexane, n-Hexadecane, toluene, and xylene were purchased from Sisco Research Laboratories (Mumbai, India). Kaolin clay, Nutrient agar, DMEM (Dulbecco's Modified Eagle's Medium), FBS (Fetal Bovine Serum) and absolute alcohol were obtained from HiMedia (Mumbai, India). All chemicals and reagents used were of analytical and ultrapure grade.

\section{Bacterial Strain and Culture Conditions}

The probiotic bacterial strain, DM-15, was isolated from the polyherbal fermented traditional medicine (Dasamoolarishta) of Indian Ayurveda. Strain DM-15 can synthesize EPS on ruthenium red milk agar (Vinothkanna and Sekar, 2019) and it was identified by biochemical tests and molecular characterization by $16 \mathrm{~S}$ rRNA gene sequencing (Vinothkanna and Sekar, 2019). The 16S rRNA sequences were submitted to GenBank with an accession number of MW031905, and the phylogenetic analysis was performed by the neighbor-joining method using MEGA software (version 7.0). Strain DM-15 was routinely cultured on nutrient agar (NA) plates, and the seed culture was prepared in lysogeny broth and incubated at $30^{\circ} \mathrm{C}$ for $24 \mathrm{~h}$. The EPS production was carried out in $500 \mathrm{~mL}$ of Erlenmeyer flask containing $100 \mathrm{~mL}$ of lysogeny broth medium amended with $2 \%$ sucrose. About $2 \%$ seed culture $\left(\sim 10^{6}\right.$ cells $\mathrm{mL}^{-1}$ ) was inoculated into the production medium and incubated at $30^{\circ} \mathrm{C}$ for 5 days (Vinothkanna et al., 2021). 


\section{Extraction and Purification of Exopolysaccharide From Strain DM-15}

After the incubation, the bacterial fermented broth was centrifuged at $8,000 \times \mathrm{g}$, and cell-free supernatant (CFS) was collected. The pooled CFS was thermally treated at $80^{\circ} \mathrm{C}$ for $20 \mathrm{~min}$ to deactivate the carbohydrate polymer degrading enzymes. The CFS was concentrated in a rotary evaporator, and two volumes of absolute ice-cold ethanol (99\%) were added to the CFS and kept at $4^{\circ} \mathrm{C}$ for $24 \mathrm{~h}$. The crude EPS precipitate was then recovered by centrifugation at $12,000 \times \mathrm{g}$ for $20 \mathrm{~min}$ at $4^{\circ} \mathrm{C}$, and the precipitate was dissolved in deionized water. Next, the crude EPS was dialyzed against sterile deionized water for $12 \mathrm{~h}$ at $4^{\circ} \mathrm{C}$. In addition, EPS was purified using ion-exchange DEAE-Sepharose fast flow column $(1.6 \times 25 \mathrm{~cm})$ with sodium chloride $(0-0.7 \mathrm{M})$ gradient as the eluent at a flow rate of $36 \mathrm{~mL} / \mathrm{h}$ by column chromatography. Gel-filtration chromatography was performed using a Sepharose- $4 \mathrm{~B}$ column $(1.6 \times 95 \mathrm{~cm})$ with deionized water as the eluent at a flow rate of $12 \mathrm{~mL} / \mathrm{h}$ (Sun et al., 2015). The eluted fractions were periodically checked for the carbohydrate content by the phenol-sulfuric acid assay. Following purification, the EPS fractions were pooled, lyophilized, and used for further characterization.

\section{Characterization of the Purified Exopolysaccharide Chemical Constituents Analysis}

About $100 \mathrm{mg}$ of lyophilized EPS was dissolved in deionized water, and the total carbohydrate was analyzed by a phenol sulfuric acid method where glucose was used as a standard (Dubois et al., 1956). Total protein was determined by Bradford assay with bovine serum albumin (BSA) as a standard (Bradford, 1976). The sulfate content was estimated using $\mathrm{K}_{2} \mathrm{SO}_{4}$ as a standard according to the method described in previous literature (Terho and Hartiala, 1971).

\section{Monosaccharide Composition and Molecular Weight Analysis}

Briefly, 2 M TFA was used to hydrolyze $5 \mathrm{mg}$ of purified EPS at $120^{\circ} \mathrm{C}$ for $2 \mathrm{~h}$. For monosaccharide composition analysis, about $10 \mu \mathrm{L}$ of hydrolyzed EPS was injected into GC-MS (QP-2010; Shimadzu Corporation, Japan), equipped with Rtx column (60 $\mathrm{m} \times 0.25 \mathrm{~mm}$ I.D $\times 0.25 \mu \mathrm{m}$ thickness (Restek, United States). The chromatographic conditions used were as follows: Helium was used as a carrier gas (99.99\% purity) with a flow rate of $10 \mathrm{~mL} \mathrm{~min}{ }^{-1}$. The oven temperature was initially set at $150^{\circ} \mathrm{C}$ for $1 \mathrm{~min}$, then elevated to $300^{\circ} \mathrm{C}$ at a rate of $8^{\circ} \mathrm{C} / \mathrm{min}$, and subsequently increased to $320^{\circ} \mathrm{C}$ at a rate of $7^{\circ} \mathrm{C} / \mathrm{min}$ for $10 \mathrm{~min}$. The ion source and interface temperatures were set at $230^{\circ} \mathrm{C}$ and $300^{\circ} \mathrm{C}$, respectively. The mass ion $(\mathrm{m} / \mathrm{z})$ range was $50-500$. The retention time (RT) of the monosaccharides present in the purified EPS was compared to that of monosaccharide standards (glucose, galactose, rhamnose, mannose, xylose, and arabinose) (Ayyash et al., 2020).

The molecular weight of the EPS was determined by sizeexclusion chromatography equipped with a TSK Gel G5000PW column $(7.5 \times 300 \mathrm{~mm}$, Tosoh Biosciences $)$. The column was equilibrated with $50 \mathrm{mM}$ ammonium acetate buffer $(\mathrm{pH}$ 5.5) and calibrated. Dextran standards $(1,189,759,511$, and $167 \mathrm{kDa})$ and glucose, $50 \mu \mathrm{L}$ EPS solution $(2 \mathrm{mg} / \mathrm{ml})$ were separately loaded onto the column and were eluted with $50 \mathrm{mM}$ ammonium acetate buffer (pH 5.5) at $1 \mathrm{~mL} \mathrm{~min}^{-1}$ (Sun et al., 2015). An evaporative light scattering detector was used to detect soluble components eluted from the column, and data were collected and processed by Agilent ChemStation software (Agilent Technologies, United States).

\section{Spectral Analyses}

About $1 \mathrm{mg} \mathrm{mL}-1$ of purified EPS was dissolved in deionized water, and the absorbance spectra were measured at a range of 190-800 nm using a UV-VIS spectrophotometer (Jasco V-650, Tokyo, Japan) (Zhou et al., 2016). The lyophilized EPS $(10 \mathrm{mg})$ was homogenized with potassium bromide $(\mathrm{KBr})$ and pressed into a pellet $(1 \mathrm{~mm}$ thickness, $10 \mathrm{~mm}$ diameter). Fourier-transform infrared (FT-IR) (PerkinElmer, Spectrum Two, United States) spectrum was recorded from 4,000 to $400 \mathrm{~cm}^{-1}$ for the detection of major functional groups present in the purified EPS (Vinothkanna et al., 2021). In addition, the crystalline quality, phase composition, purity, and crystal structure of the EPS were characterized by an X-ray diffractometer (D/MAX Ultima III, Rigaku Corporation, Tokyo, Japan) with $\mathrm{Cu}-\mathrm{K} \alpha$ radiation (1.54056 $\AA$ ) over a $2 \theta$ Scan range of $10^{\circ}-80^{\circ}$. The step length and step time used were $0.01^{\circ}$ and $0.1 \mathrm{~s} / \mathrm{step}$, respectively (Mathivanan et al., 2021).

Briefly, $30 \mathrm{mg}$ of EPS was partially hydrolyzed with $0.1 \mathrm{M}$ TFA at $100^{\circ} \mathrm{C}$ for $60 \mathrm{~min}$. The partially hydrolyzed EPS was further dialyzed against deionized water and lyophilized (Noseda et al., 2020). Finally, the partially hydrolyzed EPS was dissolved in $99.99 \%$ deuterium oxide $\left(\mathrm{D}_{2} \mathrm{O}\right) .{ }^{1} \mathrm{H}$ NMR $\left(5 \mathrm{mg} \mathrm{mL}^{-1}\right),{ }^{13} \mathrm{C}$ NMR (40 mg mL ${ }^{-1}$ ), and two-dimensional (2D) NMR analyses such as ${ }^{1} \mathrm{H}-{ }^{1} \mathrm{H}$ correlated spectroscopy (COSY) and ${ }^{13} \mathrm{C}^{-1} \mathrm{H}$ heteronuclear single quantum coherence (HSQC) were recorded at $400 \mathrm{MHz}$, Bruker Avance spectroscopy (Bruker Co., Billerica, MA), respectively (You et al., 2020).

\section{Microscopic Analysis}

The topographical image of purified EPS was analyzed by atomic force microscopy (AFM; Agilent 5500 model, United States). About $1 \mathrm{mg} \mathrm{mL}^{-1}$ of purified EPS was suspended in deionized water and kept in a water bath at $50^{\circ} \mathrm{C}$ under sonication. The completely dissolved EPS was chilled to room temperature and diluted to $10 \mu \mathrm{g} \mathrm{mL}^{-1}$ concentration. About $5 \mu \mathrm{L}$ of EPS aqueous solution was fixed on a fresh silicon material by spincoating method and desiccated overnight and studied using AFM with non-contact-mode (Vinothkanna et al., 2021). The surface microstructure of the purified EPS was analyzed using a field emission scanning electron microscope (FE-SEM; Carl ZeissSigma model, Germany). The purified EPS was mounted onto an aluminum metal stub and gold-sputtered with $10 \mathrm{~nm}$ thickness. The FE-SEM micrographs were obtained at an accelerating voltage of $20 \mathrm{kV}$ ( Li et al., 2015). 


\section{Flocculation Activity of the Exopolysaccharide}

About $1 \mathrm{~mL}$ of EPS (5-50 $\mathrm{mg} \mathrm{L}^{-1}$ ) was mixed with $8 \mathrm{~mL}$ kaolin suspension $\left(5 \mathrm{~g} \mathrm{~L}^{-1}\right)$ and $1 \mathrm{~mL}$ of calcium chloride solution (1\%) in a test tube (Sathiyanarayanan et al., 2014) and vortexed well and left to stand for $5 \mathrm{~min}$. The absorbance of the upper layer was measured at $550 \mathrm{~nm}$ using a UV-VIS spectrophotometer (Jasco V-650, Tokyo, Japan), wherein sterile distilled water was used as a control. Flocculation activity (\%) of the purified EPS was calculated as follows:

$$
f_{e}=\text { Control }- \text { Sample/Control } \times 100
$$

\section{Emulsification Property of the Exopolysaccharide}

About $2 \mathrm{~mL}$ of the purified EPS $(0.025,0.5$, and $1 \%$ ) was mixed with polar and non-polar solvents (Benzene, n-Hexane, $\mathrm{n}$-Hexadecane, Toluene, and Xylene) at a 1:1 ratio (v/v). The mixture was vortexed well and left to stand at room temperature for $24 \mathrm{~h}$, and the emulsifying index $\left(E_{h}\right)$ was calculated as follows:

$$
E_{h}=\left(H_{E L} / H_{S}\right) \times 100
$$

where $H_{E L}$ is the emulsion layer height, and HS is the solution mixture's total height (Abid et al., 2021).

\section{Antioxidant Potential of the Exopolysaccharide}

The antioxidant activity of the purified EPS $\left(0.5-3.0 \mathrm{mg} \mathrm{mL}^{-1}\right)$ was evaluated by different methods such as DPPH, ABTS, and nitric oxide (NO) radical scavenging test (Ma et al., 2018). In addition, the absorbance of the reaction mixture was measured by UV-VIS spectrophotometer (JASCO, Model V-650, Japan) at $517 \mathrm{~nm}(0.2 \mathrm{M} \mathrm{DPPH}), 734 \mathrm{~nm}$ (7 mM ABTs), and $546 \mathrm{~nm}$ ( $5 \mathrm{mM}$ Sodium nitroprusside), respectively. L-Ascorbic acid (0.5-3.0 mg $\mathrm{mL}^{-1}$ ) and deionized water were used as the positive and negative controls, respectively (Ma et al., 2018; Sivasankar et al., 2018; Vinothkanna et al., 2021).

\section{Anticancer Potential of the Purified Exopolysaccharide Cytotoxicity Assay}

Cytotoxic activity of the EPS was tested against the human lung cancer cell line (A549) by MTT assay. Briefly, A549 cells were cultured in 96 well plates (flat bottom) containing the mixture of DMEM, FBS (10\%), penicillin $\left(100 \mathrm{U} \mathrm{mL}^{-1}\right)$, and streptomycin $\left(100 \mathrm{mg} \mathrm{L}^{-1}\right)$ under the humidified environment $\left(37^{\circ} \mathrm{C}, 5 \% \mathrm{CO}_{2}\right)$ for $24 \mathrm{~h}$. Various concentrations $(10-100 \mu \mathrm{g}$ $\left.\mathrm{mL}^{-1}\right)$ of the purified EPS $(200 \mu \mathrm{L})$ was mixed with A549 cells at a concentration of $5 \times 10^{3}$ cells/well and left to stand for $24 \mathrm{~h}$ at $37^{\circ} \mathrm{C}$. Then $20 \mu \mathrm{L}$ of MTT reagent $\left(5 \mathrm{mg} \mathrm{mL}^{-1}\right.$ in phosphate-buffered saline) was added to the reaction wells and allowed to react for $4 \mathrm{~h}$ (Vinothkanna et al., 2021). Further, the purple formazan crystals were dissolved by adding 100 $\mu \mathrm{L}$ of deionized water. The reduction of MTT-formazan was determined at $570 \mathrm{~nm}$ using a microplate reader (Bio-Rad, iMark, United States). Cellular inhibitory effect (\%) was determined using the following formula:

$$
\text { Cellviability }(\%)=\mathrm{A}_{\text {Control }}-\mathrm{A}_{\text {Treatedcells }} / \mathrm{A}_{\text {Control }} \times 100 \text { (3) }
$$

\section{Acridine Orange/Ethidium Bromide and} 4',6-Diamidino-2-Phenylindole Staining

The purified EPS ( $\mathrm{IC}_{50}$ dose) and A549 tumor cells were mixed and incubated for $24 \mathrm{~h} 37^{\circ} \mathrm{C}$ under a $5 \% \mathrm{CO}_{2}$ environment. The treated cells were harvested and washed with phosphate-buffered saline. About $25 \mu \mathrm{L}$ of AO/EB (Kasibhatla et al., 2006) and DAPI (Wang et al., 2019) stains were mixed with the EPS-treated cancer cells on a glass slide and observed under a fluorescence microscope (Carl Zeiss, Axioscope2plus).

\section{Statistical Analysis}

All experiments were performed in triplicate, and the data were represented as mean \pm standard deviation. The data of antioxidant assays were compared by two-way ANOVA using Dunnet's multiple comparison tests, and ${ }^{*} p<0.05,{ }^{* *} p<0.01$, and ${ }^{* * *} p<0.001$ were considered statistically significant.

\section{RESULTS AND DISCUSSION}

\section{Production of Exopolysaccharide}

In our previous study, probiotic strain DM-15 was isolated from the Indian Ayurvedic medicine Dasamoolarishta, and its EPS producing ability was identified (Vinothkanna and Sekar, 2019). The strain DM-15 had shown 100\% similarity with Bacillus albus reference strains during the 16S rRNA phylogenetic analysis (Figure 1), and biochemical tests also validate the Bacillus genus. Therefore, based on the biochemical and phylogenetic analysis, probiotic strain DM-15 isolated from the fermented medicine was designated as B. albus DM-15. Furthermore, the EPS production experiment showed about $290 \pm 0.78 \mathrm{mg} \mathrm{L}^{-1}$ of EPS from B. albus DM-15 after a week of incubation. This production was comparatively higher than the previously reported Bacillus spp. such as Bacillus subtilis MKU SERB2 (147.23 $\mathrm{mg} \mathrm{L}^{-1}$ ) and Bacillus sp. S-1 $\left(35 \mathrm{mg} \mathrm{L}^{-1}\right)$ isolated from fermented Sichuan pickles (Hu et al., 2019; Sathishkumar et al., 2021). The EPSs synthesis is a natural phenomenon in probiotic bacteria, and it plays a vital role in biofilm formation, bacterial adhesion, bacterial cell aggregation, water-holding ability, attracting the nutrient sources, and protective barrier (Nwodo et al., 2012).

\section{Chemical Constituents, Monosaccharide Profile, and Molecular Weight of the Exopolysaccharide}

Ion-exchange chromatography had shown two different EPS peaks from the DEAE-Sepharose column (Supplementary Figure 1). Among these, the initial fraction was too sparse to harvest; however, a substantial proportion of the subsequent fraction was appropriately collected and further subjected for 


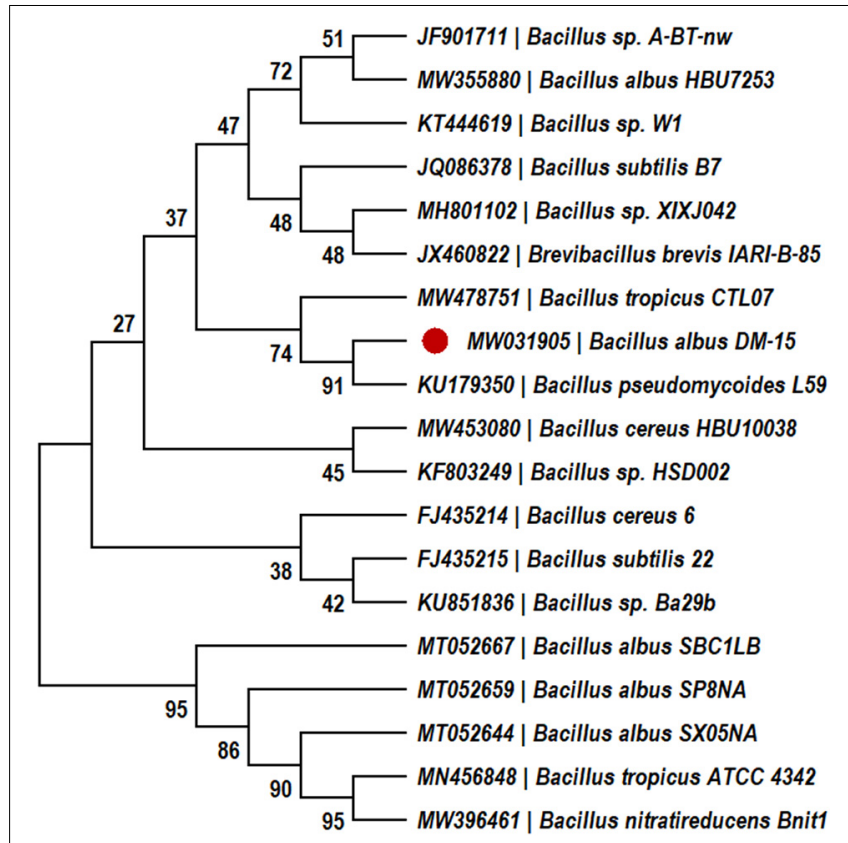

FIGURE 1 | Phylogenetic tree constructed using MEGA 7.0. by neighbor Joining method.

purification by gel-filtration chromatography using a Sepharose 4B column (Supplementary Figure 2). The single fraction was eluted from the gel-filtration chromatography and harvested and analyzed by a UV-visible spectrophotometer. UV-visible spectra indicated a band at $195 \mathrm{~nm}$, and no other absorbance peaks were detected between 260 and $290 \mathrm{~nm}$ (Supplementary Figure 3), which validates the purity of the EPS (Zhou et al., 2016). Sizeexclusion chromatography indicated that the molecular weight of the purified EPS was approximately $240 \mathrm{kDa}$. The total carbohydrate, protein, and sulfate content were 852.78, 27.51, and $119.71 \mathrm{mg} \mathrm{g}^{-1}$. Carbohydrate contents of the EPSs were higher than protein and sulfated content, a typical feature that was observed with other bacterial EPSs (Sathiyanarayanan et al., 2014, 2016). The monosaccharide composition analysis had shown the presence of glucose, galactose, xylose and rhamnose in the GC-MS chromatogram (Supplementary Figure 4), which confirms the heteropolymeric nature of the EPS purified from B. albus DM-15. The peak area, retention time, and mass ratio were summarized in Supplementary Table 1. Glucose (71.32\%) had shown a higher molar percentage followed by galactose $(13.55 \%)$, xylose $(9.38 \%)$, and rhamnose $(5.75 \%)$, respectively. Similar monosaccharide composition was identified from B. tequilensis FR9M76, B. licheniformis PASS26, and $B$. licheniformis BL-P1, where five or six monosaccharides composed the polymeric structure of the EPS (Rani et al., 2017; Insulkar et al., 2018; Xu et al., 2019). The monosaccharide composition may vary from strain to strain in the same species due to the influences of nutrients in the growth medium and other external variables such as $\mathrm{pH}$, water activity, temperature, etc. (Angelin and Kavitha, 2020).

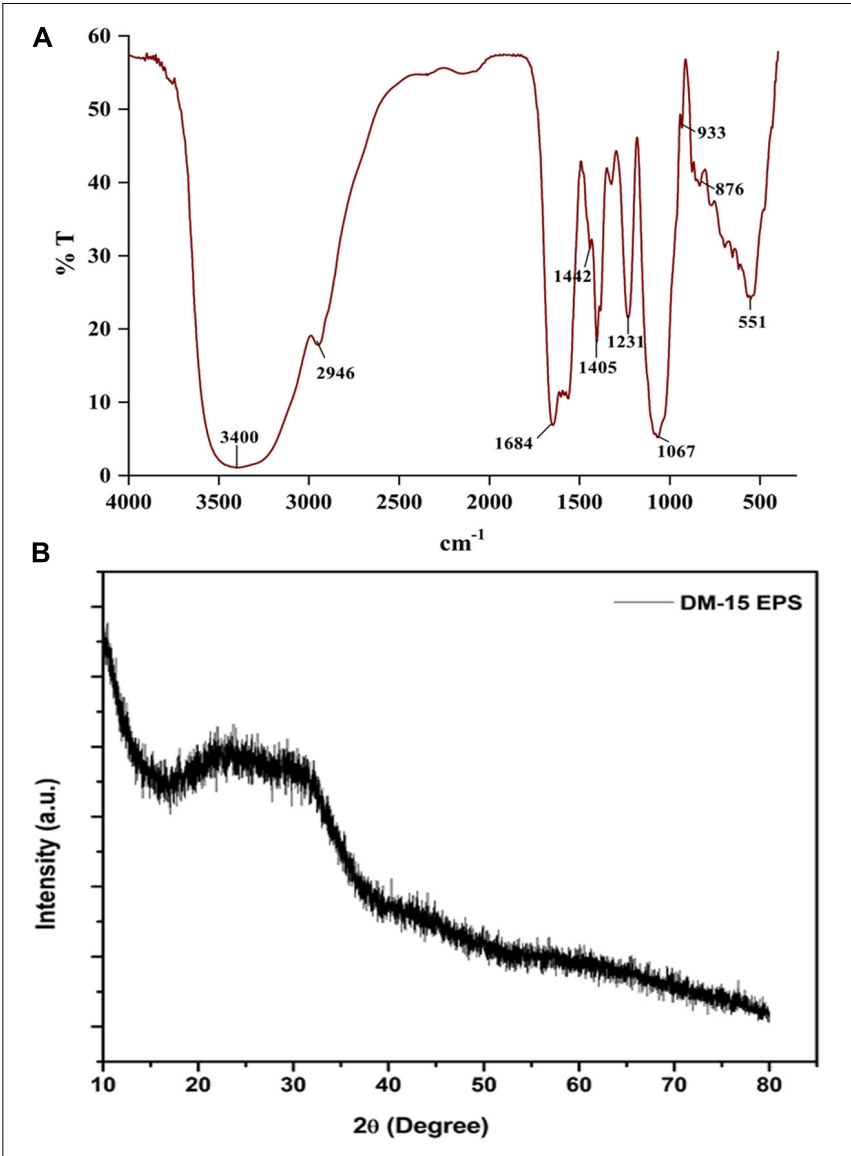

FIGURE 2 | (A) FT-IR spectrum and (B) XRD pattern of the EPS purified from B. albus DM-15.

\section{Structural Properties of the Exopolysaccharide}

\section{Fourier-Transform Infrared Analysis}

The FT-IR spectra revealed distinct polysaccharide functional groups at 3,400,2,946, 1,684, 1,405, 1,231, and $1,067 \mathrm{~cm}^{-1}$ (Ramamoorthy et al., 2018). A strongly stretched band at $3,400 \mathrm{~cm}^{-1}$ indicated the hydroxyl functional group $(-\mathrm{OH})$ (Figure 2A). The band stretched at $2,946 \mathrm{~cm}^{-1}$ corresponds to the bending vibrations of the $\mathrm{C}-\mathrm{H}$ group (Sathiyanarayanan et al., 2016; Park et al., 2022). An intense peak recorded at $1,684 \mathrm{~cm}^{-1}$ related to the carbonyl $(C=\mathrm{O})$ bending vibration (Sardari et al., 2017; Park et al., 2022). The absorption band at $1,405 \mathrm{~cm}^{-1}$ indicates the characteristics of the $\mathrm{COO}$ group. The peaks at 1,231 and 1,067 $\mathrm{cm}^{-1}$ might be the pyranose ring (Vijayabaskar et al., 2011). A solid peak at $933 \mathrm{~cm}^{-1}$ due to the presence of glycosyl residue, particularly by the $\beta$-pyranose configuration in EPS. The weak band at $876 \mathrm{~cm}^{-1}$ corresponds to the pyranose ring's of the monosaccharides (Li et al., 2015; Saravanakumar et al., 2021). The absorption signal at $834 \mathrm{~cm}^{-1}$ is assigned to $\mathrm{C}=\mathrm{O}=\mathrm{S}$ elastic vibration. A short band at $618 \mathrm{~cm}^{-1}$ indicates the adjustable pulse of alkynes and an intense peak at $551 \mathrm{~cm}^{-1}$ typical signature of alkynes and aldehydes. Overall, the FTIR spectrum authenticates the carbohydrate polymeric functional 
groups, playing a significant role in the functional and biological activities of the EPS (Sathiyanarayanan et al., 2016).

\section{X-Ray Diffraction Analysis}

The diffractogram demonstrated a significant broad nonsymmetric signal found at $23.8^{\circ}(2 \theta)$, which indicates the amorphous (non-crystalline) nature of the EPS (Figure 2B). Similar non-crystalline EPS have been identified from L. fusiformis KMNTT-10 and B. cereus KMS3-1 (Krishnamurthy et al., 2020; Mathivanan et al., 2021). Amorphous natural biopolymers can be used as thickening agents in the food processing industries apart from their application to produce edible films and coatings (Kumar Bajaj et al., 2015).

\section{Nuclear Magnetic Resonance Spectroscopic Analysis} NMR spectra of the partially hydrolyzed EPS were recorded with a $400 \mathrm{MHz}$ NMR spectrometer. Figure 3A shows the ${ }^{1} \mathrm{H}$ NMR spectrum of the EPS, and most of the signals were clustered between $\delta 3.23$ and $\delta$ 5.10. The presence of distinct signals at $\delta 4.85, \delta 4.64, \delta 4.57$, and $\delta 4.55$ correspond to anomeric protons with $J=7-8 \mathrm{~Hz}$ demonstrates that four $\beta$-isomer sugar units were present in the mixture. The remaining four sets of signals for anomeric protons at $\delta 5.26, \delta 5.22, \delta 5.18$, and $\delta$ 5.10 with $J=34 \mathrm{~Hz}$ implies that $\alpha$-anomers were also present. Since the EPS was subjected to hydrolysis using trifluoroacetic acid, the free sugar units adopt $\alpha$ and $\beta$ forms. The solvent residual peak (deuterium oxide) was obtained at $\delta 4.79 \mathrm{ppm}$ and one of the anomeric protons, thus confirmed by $2 \mathrm{D}^{1} \mathrm{H}_{-}{ }^{13} \mathrm{C}$ HSQC NMR. Similarly, in the ${ }^{13} \mathrm{C}-\mathrm{NMR}$, the anomeric carbons appeared at anomeric carbon regions $\delta$ 96.61, 95.68, 92.20, 93.97, 93.46, $92.2492 .03 \mathrm{ppm}$, which confirms the carbohydrate polymer (Figure 3B).

The ${ }^{1} \mathrm{H}^{-}{ }^{1} \mathrm{H}$ COSY technique was used to identify the coupled protons of each sugar unit. The cross-correlation sequence from the $\alpha$ and $\beta$ anomeric protons with other protons in the ${ }^{1} \mathrm{H}-{ }^{1} \mathrm{H}$ COSY spectrum confirmed D-Glucose and D-Galactose $\mathrm{D}$-Xylose, and L-Rhamnose, which were assigned as residue A, $\mathrm{B}, \mathrm{C}$, and $\mathrm{D}$, respectively (Figure $4 \mathrm{~A})$. The set of $\alpha / \beta$ signals at 反 5.22/4.64 $\left(\mathrm{H}_{1}\right), 3.50 / 3.23\left(\mathrm{H}_{2}\right), 3.77 / 3.92\left(\mathrm{H}_{3}\right), 3.91 / 3.62\left(\mathrm{H}_{4}\right)$, 3.97/3.99 $\left(\mathrm{H}_{5}\right), 3.72 / 3.82\left(\mathrm{H}_{6}\right)$ were assigned to D-Glucose. The signals at $\delta 5.26 / 4.55,3.79 / 3.23,3.82 / 3.48,3.89 / 3.92,4.08 / 3.70$, and $3.71 / 3.74$ were assigned to $\alpha / \beta$ form of $D$-Galactose. The presence of $\delta 3.80 / 3.87\left(\mathrm{H}_{5}\right)$ corresponds to methylene protons confirms the existence of $\alpha$ and the $\beta$ state of D-Xylose in the solution. Furthermore, cross-correlation sequence in the ${ }^{1} \mathrm{H}$ ${ }^{1} \mathrm{H}$ COSY spectrum, the signal at $\delta 5.18 / 4.57$ with signals at $\delta$ $3.52 / 3.50,3.63 / 3.68,3.63 / 4.07,3.91 / 3.87$ were assigned to $\alpha / \beta$ form of D-Xylose. The exclusive signal at $\delta 1.28$ of methyl group and cross-correlation sequence with anomeric proton leads to the assignment of signals at $\delta 5.10 / 4.85\left(\mathrm{H}_{1}\right), 3.91 / 3.91\left(\mathrm{H}_{2}\right)$, 3.80/3.80 $\left(\mathrm{H}_{3}\right), 3.48 / 3.43\left(\mathrm{H}_{4}\right), 3.88 / 3.85\left(\mathrm{H}_{5}\right), 1.28 / 1.28\left(\mathrm{H}_{6}\right)$ to $\alpha / \beta$ form of $L-R h a m n o s e$. Cross peaks of coupled protons in sugar residues $\mathrm{H}_{5}-\mathrm{H}_{6}$ coupling of $\beta$-L-Rhamnose were not shown in Figure 4A. A similar proton NMR signal was obtained at $\delta 1.28$ for Rhamnose residue (Sun et al., 2020).

Single bond correlations between ${ }^{1} \mathrm{H}$ and ${ }^{13} \mathrm{C}$ were established using the HSQC technique to assign the ${ }^{13} \mathrm{C}$ signals of the compounds and were shown in Table $\mathbf{1}$ and Figure $4 \mathbf{B}$. The anomeric $\alpha$ and $\beta$ carbons of D-Glucose, D-Galactose, D-Xylose and L-Rhamnose were assigned to $\delta 92.02 / 95.94$, 92.02/96.59,92.11/96.45, and 93.94/92.05 respectively. The other carbon signals were assigned and represented (Figures 3A,B and Table 1). Overall, the NMR findings strongly support the monosaccharide composition obtained from the GC-MS analysis (Supplementary Figure 4).

\section{Microscopic Observation}

The spherical lumps with an optimal height of $5.9 \mathrm{~nm}$ and fibrous chain-like characteristics were observed under AFM (Figures 5A,B). The 3-D structural view of the AFM images is shown in Figure 5C. The spherical complexes appeared much larger than the chain-like carbohydrates, demonstrating the inter/intramolecular level aggregation in EPS. The spherical, irregular spikes and chain-like structural characteristics of the purified EPS might have fibrous networks in some regions. In contrast, coarse areas were also observed, which indicates the tangled webs in the EPS. EPS from probiotic B. licheniformis AG-06 and L. plantarum YW11 exhibits similar tangled weblike structural features (Wang et al., 2015; Vinothkanna et al., 2021).

The surface characteristics and microstructure of the EPS were investigated by SEM imaging analysis. The 3-D complexity of EPS was identified and found to be stable. They have predominantly appeared as a tightly porous web-like structure with the irregular coarse surface of stacked flake-like polysaccharides at higher magnification (Figure 5D). EPS derived from B. licheniformis PASS26 and B. licheniformis AG-06 have exhibited a similar type of porous web-like with polymer matrix structure (Insulkar et al., 2018; Sathishkumar et al., 2021). These permeable web-like molecules are desirable in food industries to increase the porosity and water holding capability and strengthen the materials' functional properties.

\section{Flocculation Activity}

The purified EPS had shown a significant flocculation activity (Figure 6). The maximum flocculation activity was obtained $(73.15 \pm 1.25 \%)$ at an EPS concentration of $40 \mathrm{mg} \mathrm{L}^{-1}$. The flocculation rate was dependent on the optimum dosage, and similar patterns have been found in EPSs isolated from Pseudomonas sp. PAMC 28620 and B. cereus KMS3-1 (Sathiyanarayanan et al., 2016; Krishnamurthy et al., 2020). It has been strongly believed that the functional groups present in the EPS and molecular weight play a critical role in flocculation activity (Okaiyeto et al., 2016; Nouha et al., 2018). Earlier reports on EPSs purified from Lysinibacillus fusiformis KMNTT-10 and B. cereus KMS3-1 had shown flocculation activity of 89.66 and $88.35 \%$, respectively (Krishnamurthy et al., 2020; Mathivanan et al., 2021). At present, synthetic/inorganic flocculants are widely used in industries. However, most of them are nonbiodegradable, highly susceptible to $\mathrm{pH}$, inefficient in chilled water, and develop an undesirable odor and palatability induce harmful impacts to humans (Okaiyeto et al., 2016). Therefore, naturally extracted flocculants, especially bacterial EPSs, are recommended due to their unique characteristics: innocuous, 
A

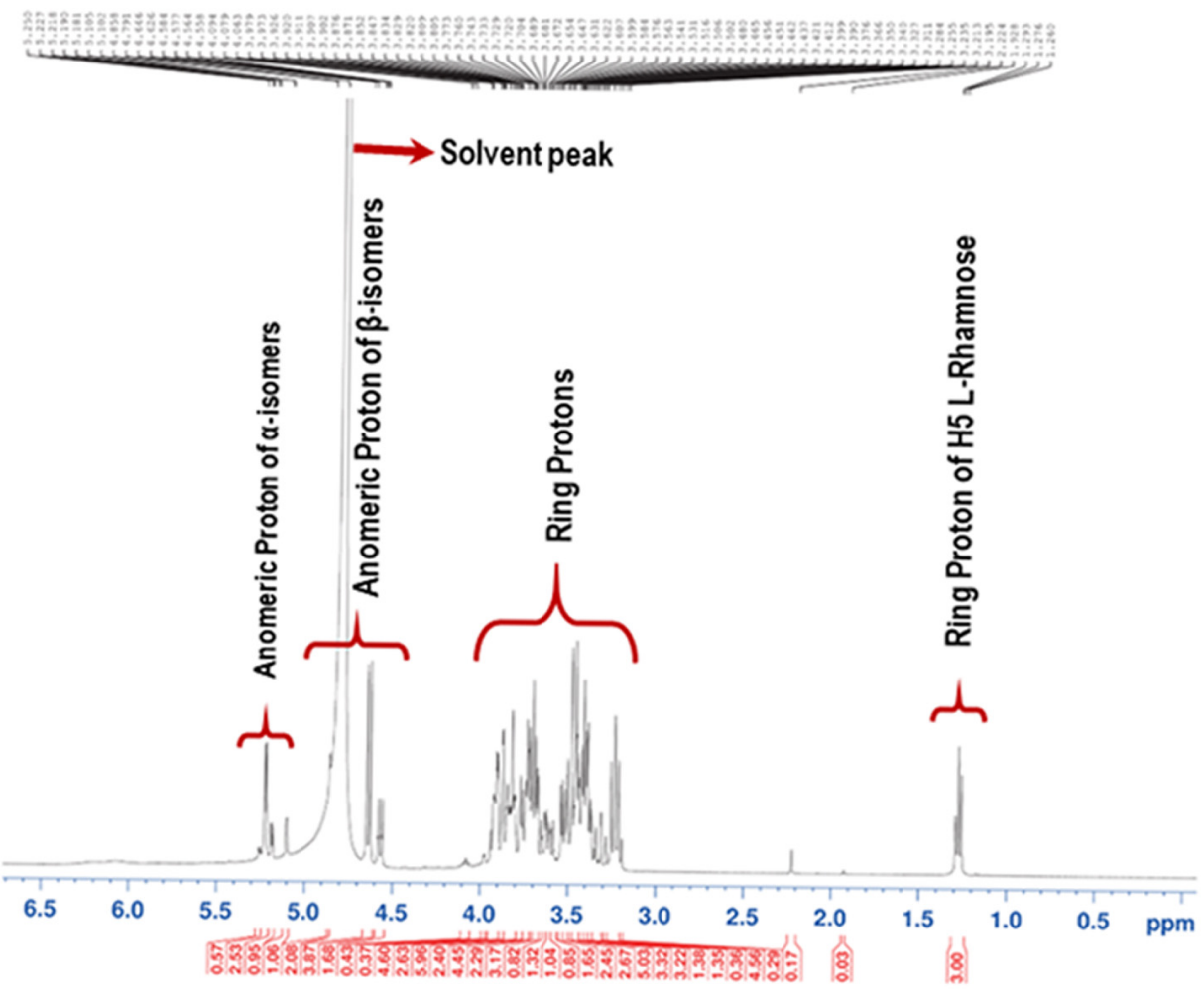

B

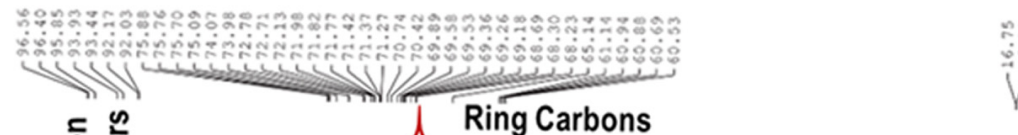

Vं

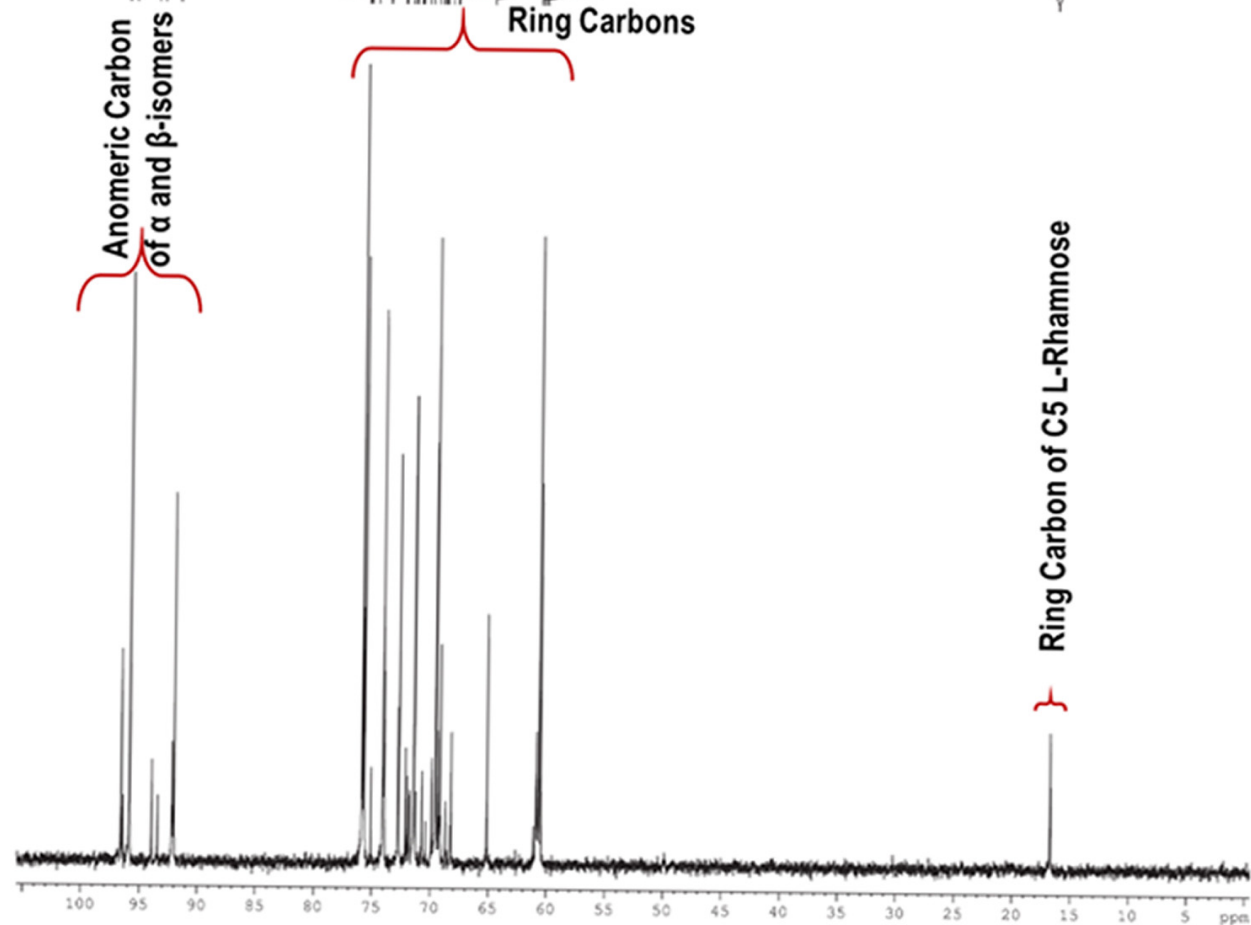

FIGURE 3 | (A) Proton $\left({ }^{1} \mathrm{H}\right)$ and (B) Carbon $\left({ }^{13} \mathrm{C}\right)$ NMR spectra of the EPS purified from B. albus DM-15. 

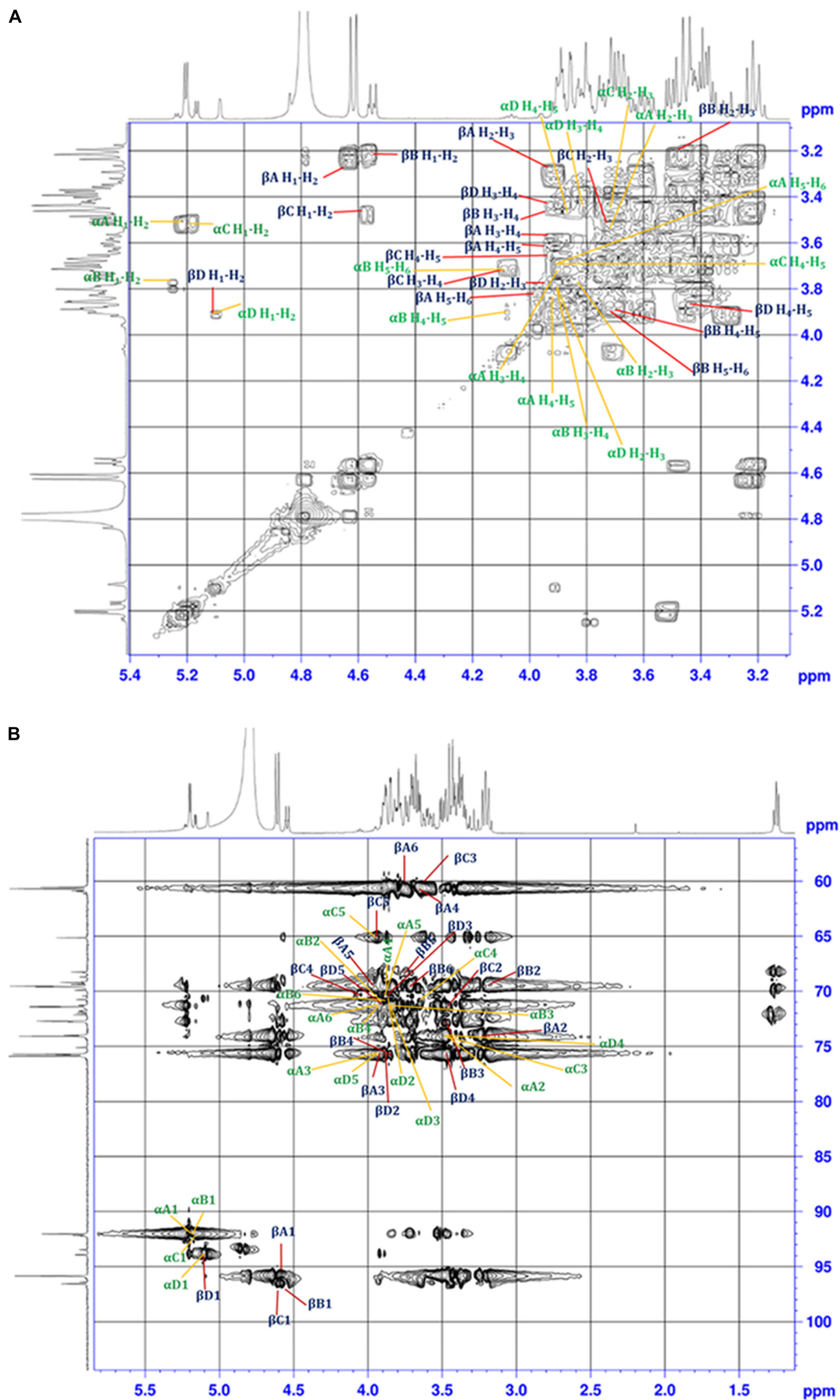

FIGURE $4 \mid$ | (A) ${ }^{1} \mathrm{H}^{-1} \mathrm{H}$ COSY, and (B) ${ }^{1} \mathrm{H}^{-13} \mathrm{C}$ HSQC 2D-NMR spectra of the EPS purified from B. albus DM-15. 
TABLE 1 | Chemical shifts (ppm) of ${ }^{1} \mathrm{H}$ and ${ }^{13} \mathrm{C}$ (in parentheses) NMR signals for the partially hydrolyzed EPS, recorded in $\mathrm{D}_{2} \mathrm{O}$ at $323 \mathrm{~K}$.

\begin{tabular}{|c|c|c|c|c|c|c|c|c|}
\hline \multirow[t]{2}{*}{ Residue } & \multirow[t]{2}{*}{ Sugar unit } & & \multicolumn{6}{|c|}{ Chemical shifts (ppm) } \\
\hline & & & $\mathrm{H}_{1} / \mathrm{C}_{1}$ & $\mathrm{H}_{2} / \mathrm{C}_{2}$ & $\mathrm{H}_{3} / \mathrm{C}_{3}$ & $\mathrm{H}_{4} / \mathrm{C}_{4}$ & $\mathrm{H}_{5} / \mathrm{C}_{5}$ & $\mathrm{H}_{6} / \mathrm{C}_{6}$ \\
\hline & & $\beta$ & $4.64 / 95.94$ & $3.23 / 74.22$ & $3.92 / 75.92$ & $3.62 / 72.95$ & $3.99 / 68.77$ & $3.72 / 60.60$ \\
\hline \multirow[t]{2}{*}{ B } & D-Galactose & $\alpha$ & $5.26 / 92.02$ & $3.79 / 70.52$ & $3.82 / 71.38$ & $3.92 / 70.54$ & $4.08 / 70.43$ & $3.71 / 71.33$ \\
\hline & & $\beta$ & $4.55 / 96.59$ & $3.23 / 69.59$ & $3.48 / 72.78$ & $3.92 / 75.79$ & $3.70 / 70.49$ & $3.74 / 68.25$ \\
\hline \multirow[t]{2}{*}{ D } & L-Rhamnose & $\alpha$ & $5.10 / 93.94$ & $3.91 / 70.61$ & $3.80 / 71.41$ & $3.48 / 74.15$ & $3.88 / 74.97$ & $1.28 / 16.79$ \\
\hline & & $\beta$ & $4.85 / 92.05$ & $3.91 / 75.79$ & $3.80 / 71.41$ & $3.43 / 75.89$ & $3.85 / 72.64$ & $1.28 / 16.79$ \\
\hline
\end{tabular}

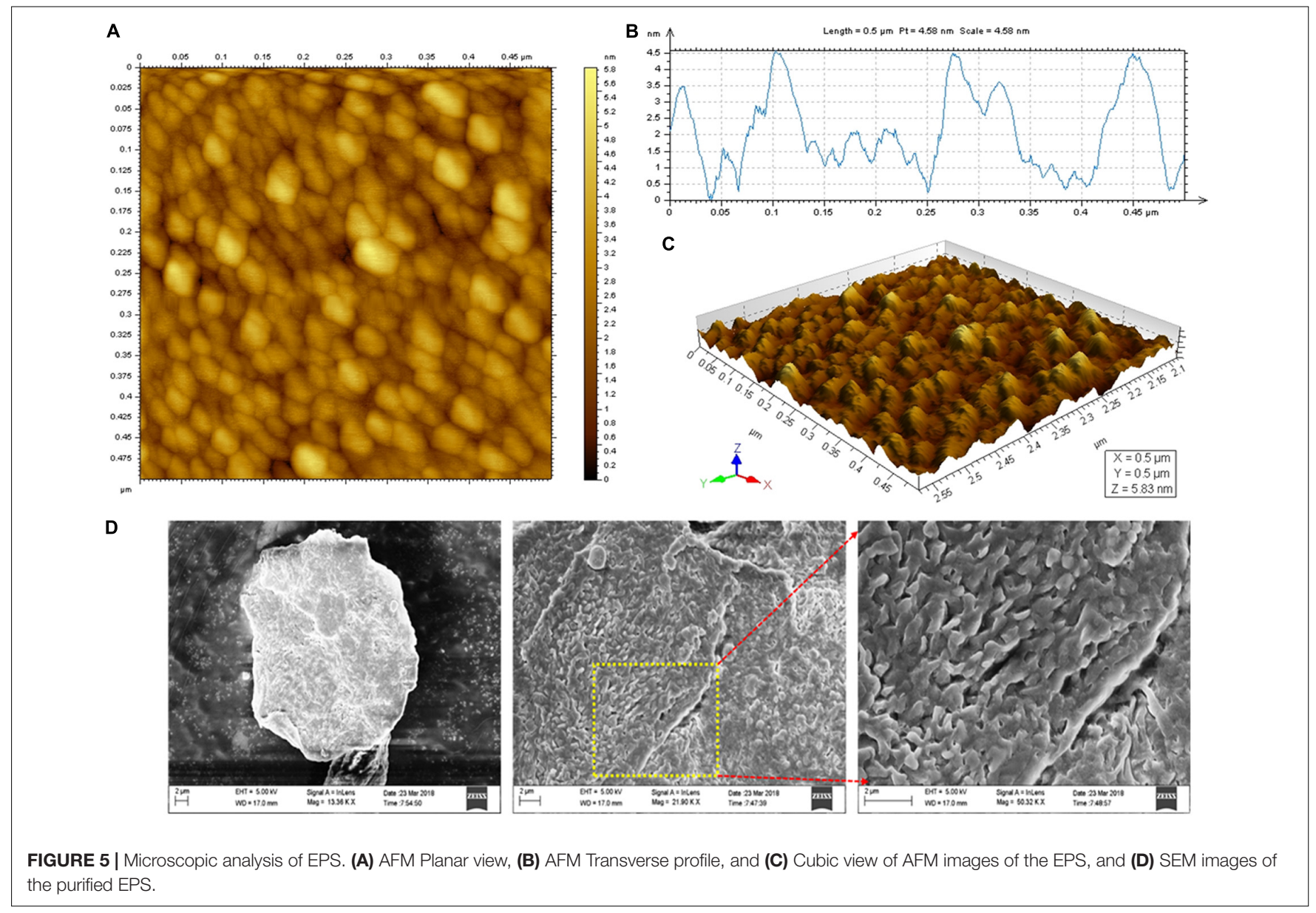

biodegradability, biocompatibility (effective in $\mathrm{pH}$, cold and warm water), and better quality flocculation efficacy (Okaiyeto et al., 2016). The EPS purified from B. albus DM-15 had shown a significant flocculation activity, which can be further exploited for commercial purposes after an intensive screening with other commercially available flocculants.

\section{Emulsification Activity}

The emulsifying activity was determined using different hydrocarbons (Figure 7). The highest emulsification was recorded at $1 \%$ of EPS concentration. The purified EPS
$(0.025 \%)$ had shown a maximum emulsification index $(67.04 \pm 1.75 \%)$ with xylene followed by hexane, toluene, n-hexadecane, and benzene after $24 \mathrm{~h}$ of incubation. Similar kinds of the emulsifying potential of the EPS have been reported ( $1 \%$ dose) from B. tequilensis $(63.64 \%)$ and B. pumilus UW-02 (68\%) (Chowdhury et al., 2011; Abid et al., 2019). The emulsification potential of the EPS is a unique characteristic, and the EPS obtained from $B$. albus DM-15 had shown a considerable emulsification activity, demonstrating the promising nature of the EPS with industrial implications. 


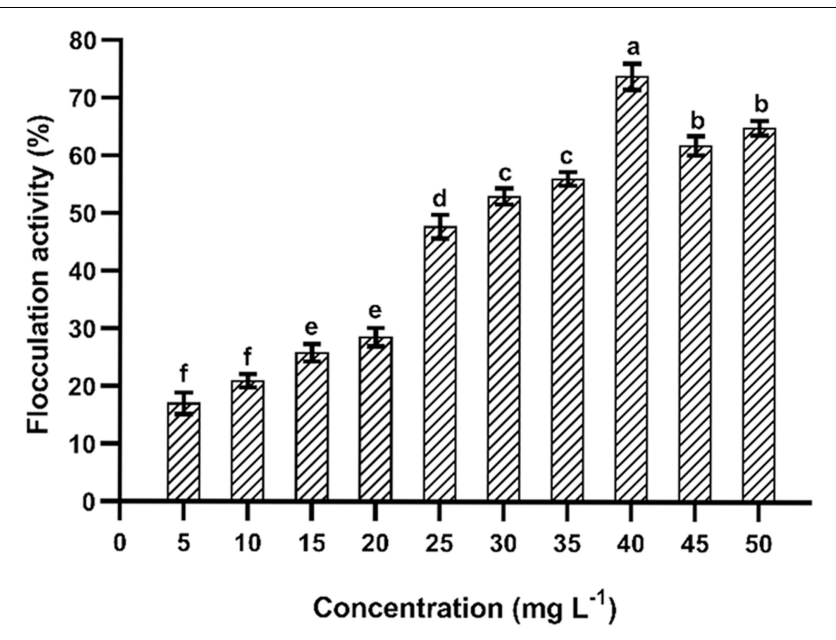

FIGURE 6 | Flocculation of EPS obtained from B. albus DM-15. The data were shown as mean $\pm \operatorname{SD}(n=3)$. Significant differences were determined by Tukey's HSD test at $p<0.05$. In addition, values with different letters (a, b, c, d, e, and f) are significantly different.

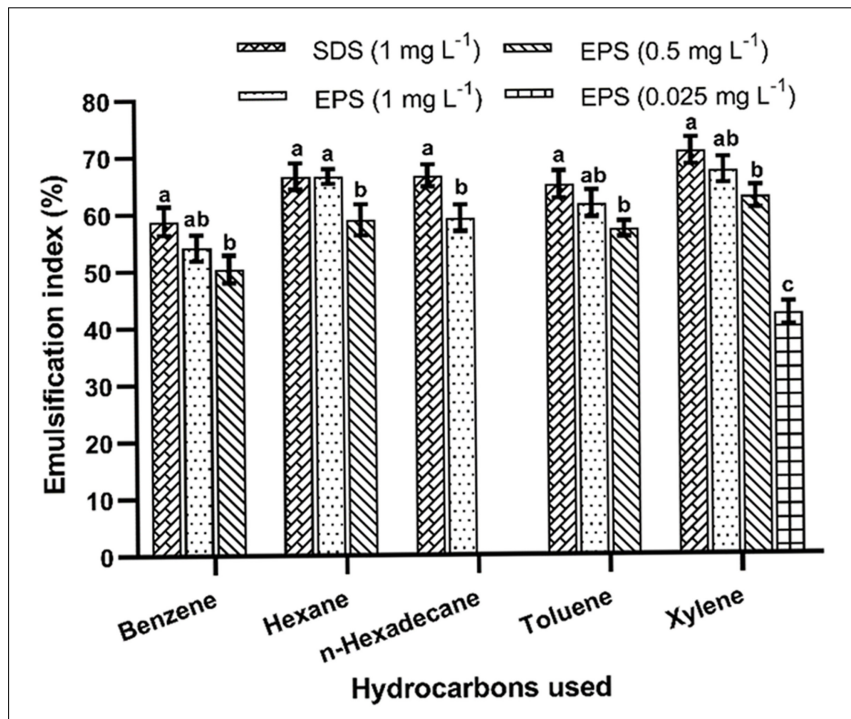

FIGURE 7 | Emulsification activities of EPS obtained from B. albus DM-15. The data were shown as mean $\pm \operatorname{SD}(n=3)$. Significant differences were determined by Tukey's HSD test at $p<0.05$. In addition, values with different letters ( $\mathrm{a}, \mathrm{b}$ and $\mathrm{c}$ ) are significantly different.

\section{Antioxidant Activities}

The purified EPS and reference standard (L-ascorbic acid) had shown their potential to scavenge DPPH radicals at various doses (0.5-3.0 $\mathrm{mg} \mathrm{mL}^{-1}$ ) (Figure 8A). About 59.91 $\pm 1.44 \%$ quenching activity was observed at $3.0 \mathrm{mg} \mathrm{mL}^{-1}$ of EPS concentration, which was significantly $(p<0.05)$ lesser than the reference standard $(82.76 \pm 1.71 \%)$. The DPPH free radical quenching activity of EPS has increased in a dose-dependent way, wherein the concentration of the EPS is directly proportional to the antioxidant activity. DPPH activity was comparatively higher than the previously reported EPSs isolated from Paenibacillus
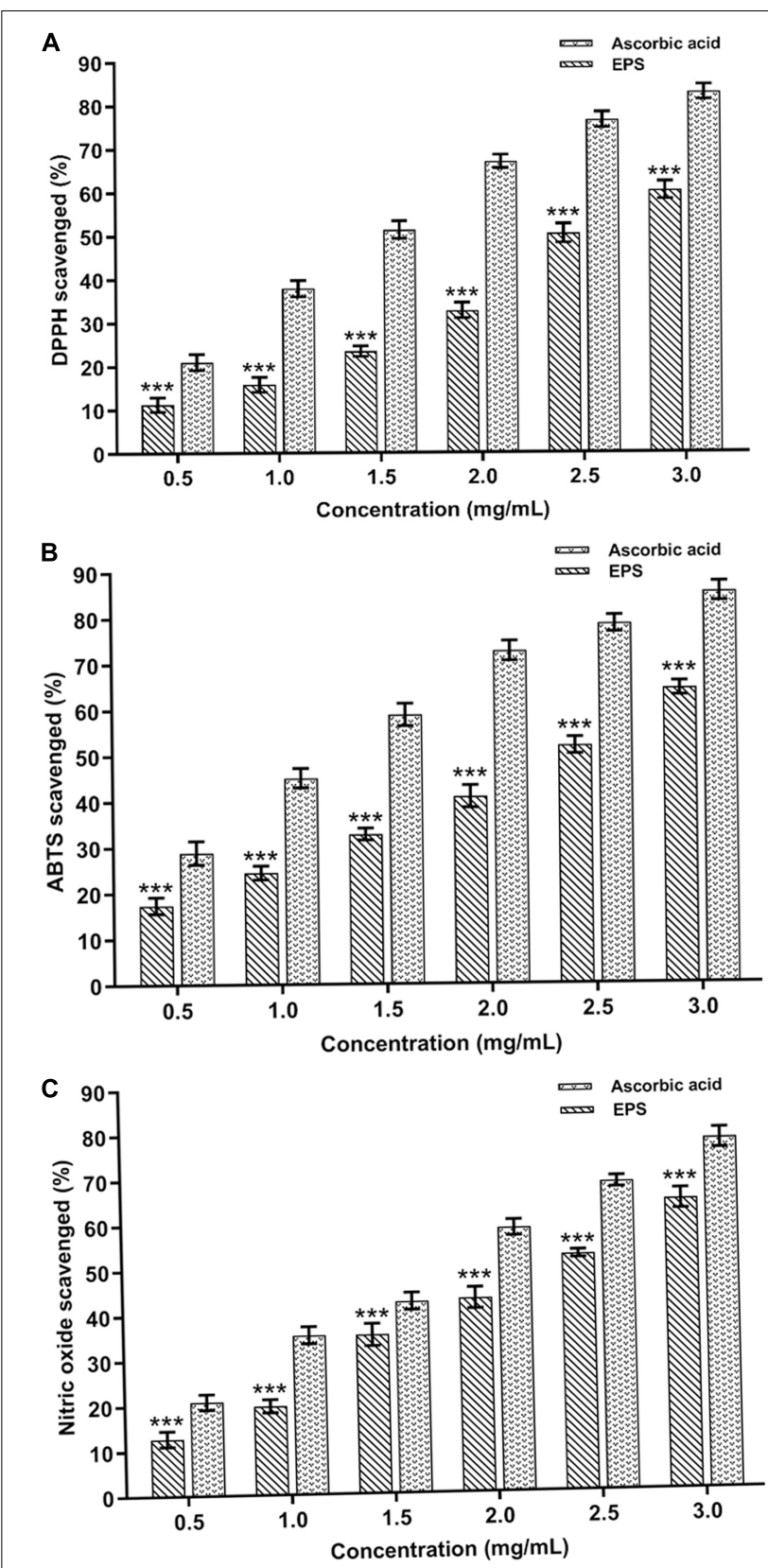

FIGURE 8 | In vitro antioxidant potential of the EPS extracted from B. albus DM-15. (A) DPPH, (B) ABTS, and (C) Nitric oxide radical scavenging activities of the EPS. The data were shown as mean $\pm \operatorname{SD}(n=3)$. The significant levels are expressed as ${ }^{\star} p<0.05,{ }^{\star \star} p<0.01$, and ${ }^{\star \star *} p<0.001$.

polymyxa EJS-3 (45.4\%) and B. aerophilus $\mathrm{rk} 1$ (57.6\%), wherein $4 \mathrm{mg} \mathrm{mL}^{-1}$ of the EPS was used for the DPPH assay (Liu et al., 2010; Gangalla et al., 2021). Furthermore, EPS exhibits the ABTS quenching activity of about $64.24 \pm 1.53 \%$ at the maximum EPS concentration of $3.0 \mathrm{mg} \mathrm{mL}^{-1}$, which is considerably lesser than L-ascorbic acid (85.99 $\pm 1.65 \%)$ (Figure 8B). The ABTS radical scavenging activity trend was similar to DPPH as the activity escalated on increasing EPS concentration. Previous studies also suggest that the EPS isolated from the B. velezensis SN-1 EPS 
(63.3\%) and Pediococcus pentosaceus M41 (48.9\%) had shown a lower ABTS radical scavenging at the maximum dose of 8 and $10 \mathrm{mg} \mathrm{mL}^{-1}$, respectively (Ayyash et al., 2020; Cao et al., 2020). The purified EPS had shown an excellent nitric acid quenching activity in a dose-dependent manner with the highest activity of $63.78 \pm 1.75 \%$ at $3.0 \mathrm{mg} \mathrm{mL}^{-1}$ of EPS concentration (Figure 8C). The results obtained from this study was highly corroborated with the EPS purified from the Lysinibacillus fusiformis KMNTT10 EPS, where $3 \mathrm{mg} \mathrm{mL}-1$ was used for nitric oxide (NO) scavenging activity (Mathivanan et al., 2021). Therefore, purified EPS might potentially combat the generation of nitric oxide radicals and manage the detrimental effects of nitric oxide. Our earlier report also showed many antioxidant activities, including DPPH (58.17 $\pm 0.054 \%)$, ABTS (70.47 $\pm 0.854 \%$ ), and NO (58.92 $\pm 0.744 \%)$, wherein cell-free supernatant of the B. albus DM-15 was used for the screening of the antioxidant activities (Vinothkanna and Sekar, 2019). The results obtained from this study were close to our previous study since the EPS was purified from the same strain DM-15. Sulfated EPS purified from Bacillus megaterium PFY-147 had shown a significant free radical scavenging activity since the sulfate group in the EPS possibly enhanced the antioxidant and probiotic activities (Pei et al., 2020). In this study, the EPS obtained from B. albus DM-15 had shown to have sulfate molecules $(119.71 \mathrm{mg} / \mathrm{g}$ ), possibly strengthening anticancer, antioxidant and probiotic properties. The functional groups present in the EPS, especially the hydroxyl group $(-\mathrm{OH})$, may neutralize the hydroxyl free radicals, thus increasing the quenching ability (Zhao et al., 2018). In addition, the FT-IR analysis also validates the presence of different functional groups (carboxylic acids, ether, alkynes, carbonyl) that may play a key role in therapeutic applications of the EPS (Xu et al., 2011; Zhao et al., 2018; Farinazzo et al., 2020). Overall, antioxidant activities of the purified EPS suggest that this EPS candidate can be exploited further in detail to fully explore the potential of EPSs from the probiotic bacteria isolated from the Indian Ayurvedic fermented medicines.

\section{Anticancer Potential of the Exopolysaccharide}

In this study, the cytotoxic effect of the EPS against A549 cells was observed with an $\mathrm{IC}_{50}$ value of $20 \pm 0.97 \mu \mathrm{g} \mathrm{mL}-1$ (Supplementary Figure 5). The cytotoxic activity of the EPS is directly proportional to the concentration of the EPS. Our results also substantiate with the EPSs purified from $B$. altitudinis MSH2014 and B. licheniformis AG-06, which inhibits the proliferation of the A549 cancer cells (Mohamed et al., 2018; Vinothkanna et al., 2021). Antiproliferative or cytotoxic activity is quite common in sulfated EPS. For example, EPS from Anoxybacillus gonensis YK25 showed considerable anticancer activity against lung cancer cells (Karadayi et al., 2021). The EPS used in this study also possess the sulfate content, which might be responsible for the cytotoxic activity.

In addition, the $\mathrm{IC}_{50}$ dose of the EPS was used to evaluate the AO/DAPI staining of A549 cancer cells (Figure 9A). The intact viable cells in the control group appeared as fluorescent green. At the same time, EPS-treated damaged cells were orange, distinctly demonstrating apoptotic characteristics such as chromatin condensation and cell shrinkages (early apoptosis) and cell
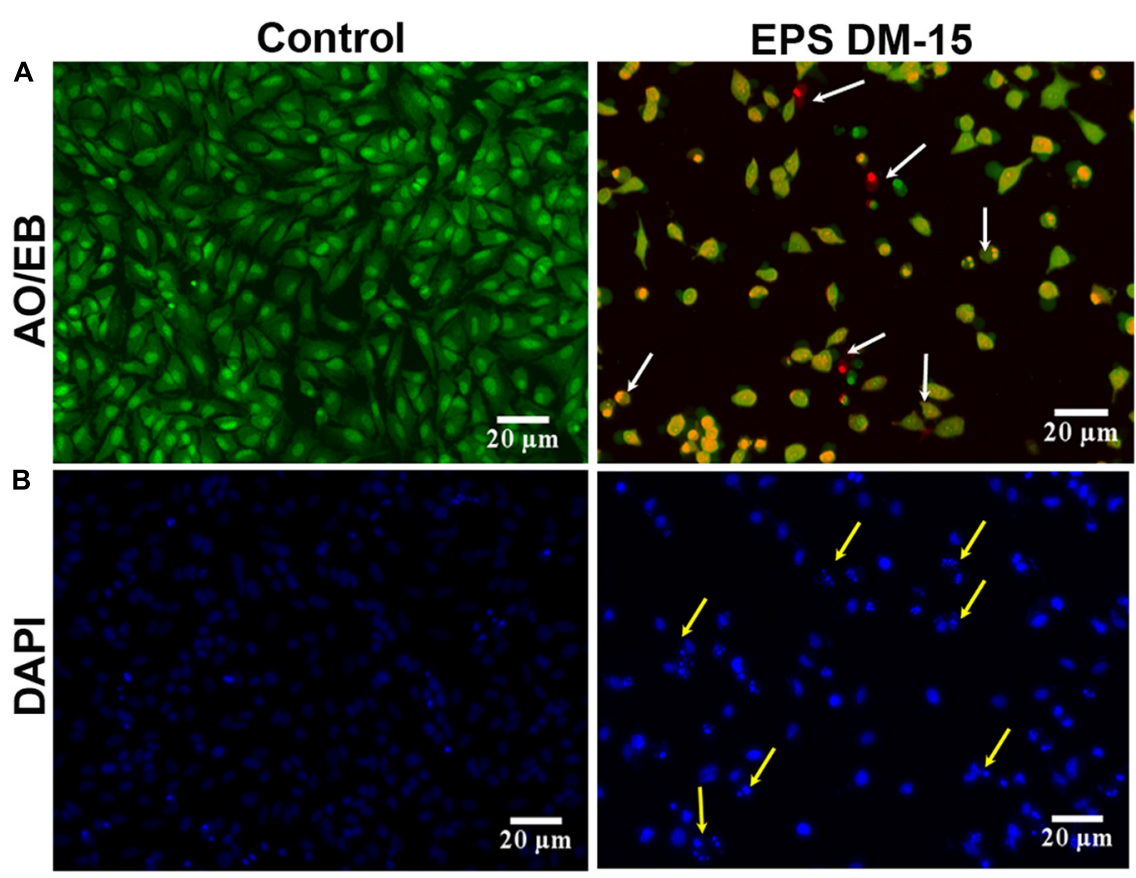

FIGURE 9 | Anticancer activity of the EPS obtained probiotic B. albus DM-15 against lung cancer cell line A549. Cytotoxic effect of the EPS against A549 cells after $24 \mathrm{~h}$ exposure. (A) AO/EB staining with the $\mathrm{IC}_{50}$ concentration of EPS. Green-colored are intact live cells, and orange-colored (white arrow) are dead exhibiting apoptotic morphology. (B) DAPI staining with the $\mathrm{IC}_{50}$ concentration of EPS revealed healthy and damaged cells (yellow arrow). 
fragmentation (late apoptosis). Also, very few cellular necroses were observed in EPS-treated cells. DAPI staining of cell nuclei treated with EPS had revealed the apoptotic and a few necrotic characters in damaged cells (Figure 9B). Other cytological and apoptotic modifications, including membrane blebbing and the development of apoptotic bodies (condensed dots), were found in EPS treated cancer cells. Furthermore, a maximum amount of damage was found in the EPS treated cells compared to control (healthy cells) (Supplementary Figure 6). It demonstrates that the EPS from B. albus DM-15 is a promising candidate against the A549 lung cancer line. Further intense studies on this EPS molecule will possibly open the doors to formulate potential EPS-based dietary supplements and natural drugs for cancer prevention and treatment, particularly lung cancer.

\section{CONCLUSION}

This study emphasizes the EPS production, purification, and characterization from $B$. albus DM-15 isolated from the Indian ayurvedic fermented medicine Dasamoolarishta. GC-MS and NMR analysis confirm the heteropolymeric nature of the purified EPS composed of glucose, galactose, xylose, and rhamnose. The purified EPS had shown a molecular weight of about $240 \mathrm{kDa}$. X-ray diffraction (XRD) analysis confirmed the noncrystalline amorphous nature of the carbohydrate polymer. AFM and SEM analyses also demonstrate the fibrous and web-like complexity with an irregular coarse surface of stacked flakelike porous nature of the EPS. Furthermore, the EPS has exhibited significant flocculation and emulsification properties. In addition, the EPS had shown potential antioxidant and anticancer activities. Therefore, EPS obtained from probiotic $B$. albus DM-15 can be further studied for nutraceutical and pharmaceutical applications.

\section{REFERENCES}

Abid, Y., Azabou, S., Blecker, C., Gharsallaoui, A., Corsaro, M. M., Besbes, S., et al. (2021). Rheological and emulsifying properties of an exopolysaccharide produced by potential probiotic Leuconostoc citreumBMS strain. Carbohydr. Polym. 256:117523. doi: 10.1016/j.carbpol.2020.1 17523

Abid, Y., Azabou, S., Joulak, I., Casillo, A., Lanzetta, R., Corsaro, M. M., et al. (2019). Potential biotechnological properties of an exopolysaccharide produced by newly isolated Bacillus tequilensis-GM from spontaneously fermented goat milk. LWT Food Sci. Technol. 105, 135-141.

Almutairi, M. H., and Helal, M. M. (2021). Biological and microbiological activities of isolated Enterobacter sp. ACD2 exopolysaccharides from Tabuk region of Saudi Arabia. J. King Saud Univ. Sci. 33:101328. doi: 10.1016/j.jksus.2020. 101328

Andrew, M., and Jayaraman, G. (2020). Structural features of microbial exopolysaccharides in relation to their antioxidant activity. Carbohydr. Res. 487:107881. doi: 10.1016/j.carres.2019.107881

Angelin, J., and Kavitha, M. (2020). Exopolysaccharides from probiotic bacteria and their health potential. Int. J. Biol. Macromol. 162, 853-865. doi: 10.1016/j. ijbiomac.2020.06.190

Ayyash, M., Abu-Jdayil, B., Olaimat, A., Esposito, G., Itsaranuwat, P., Osaili, T., et al. (2020). Physicochemical, bioactive and rheological properties of an exopolysaccharide produced by a probiotic Pediococcus pentosaceus M41. Carbohydr. Polym. 229, 115462. doi: 10.1016/j.carbpol.2019.115462

\section{DATA AVAILABILITY STATEMENT}

The original contributions presented in the study are included in the article/Supplementary Material, further inquiries can be directed to the corresponding author/s.

\section{AUTHOR CONTRIBUTIONS}

AV: conceptualization, methodology, formal analysis, validation, visualization, writing, and original draft. GS: validation, writingoriginal draft, and writing - review and editing. AR: visualization, review, and editing. KM: formal analysis and visualization. $\mathrm{KSa}, \mathrm{KSu}$, and PK: formal analysis. YM: project administration, validation, visualization, and writing-review and editing. SS: conceptualization, supervision, project administration, funding acquisition, and writing-review and editing. All authors contributed to the article and approved the submitted version.

\section{ACKNOWLEDGMENTS}

AV is thankful for the Award of UGC-RGN Fellowship. We thank TN. Narayanan Varier and TR. Sasi Varier of Ashtanga Ayurvedics (P) Ltd., Tiruchirappalli, for the Ayurvedic medicine samples.

\section{SUPPLEMENTARY MATERIAL}

The Supplementary Material for this article can be found online at: https://www.frontiersin.org/articles/10.3389/fmicb. 2022.832109/full\#supplementary-material

Bradford, M. M. (1976). A rapid and sensitive method for the quantitation of microgram quantities of protein utilizing the principle of protein-dye binding. Anal. Biochem. 72, 248-254. doi: 10.1006/abio.1976.9999

Cao, C., Li, Y., Wang, C., Zhang, N., Zhu, X., Wu, R., et al. (2020). Purification, characterization and antitumor activity of an exopolysaccharide produced by Bacillus velezensis SN-1. Int. J. Biol. Macromol. 156, 354-361. doi: 10.1016/j. ijbiomac.2020.04.024

Chowdhury, S. R., Basak, R. K., Sen, R., and Adhikari, B. (2011). Characterization and emulsifying property of a carbohydrate polymer produced by Bacillus pumilus UW-02 isolated from waste water irrigated agricultural soil. Int. J. Biol. Macromol. 48, 705-712. doi: 10.1016/j.ijbiomac.2011.02.019

Daba, G. M., Elnahas, M. O., and Elkhateeb, W. A. (2021). Contributions of exopolysaccharides from lactic acid bacteria as biotechnological tools in food, pharmaceutical, and medical applications. Int. J. Biol. Macromol. 173, 79-89. doi: 10.1016/j.ijbiomac.2021.01.110

Dubois, M., Gilles, K. A., Hamilton, J. K., Rebers, P. T., and Smith, F. (1956). Colorimetric method for determination of sugars and related substances. Anal. Chem. 28, 350-356.

Farinazzo, F. S., Valente, L. J., Almeida, M. B., Simionato, A. S., Fernandes, M. T. C., Mauro, C. S. I., et al. (2020). Characterization and antioxidant activity of an exopolysaccharide produced by Leuconostoc pseudomesenteroides JF17 from juçara fruits (Euterpe edulis Martius). Process Biochem. 91, 141-148.

Freitas, F., Alves, V. D., and Reis, M. A. (2011). Advances in bacterial exopolysaccharides: from production to biotechnological applications. Trends Biotechnol. 29, 388-398. doi: 10.1016/j.tibtech.2011.03.008 
Gangalla, R., Sampath, G., Beduru, S., Sarika, K., Govindarajan, R. K., Ameen, F., et al. (2021). Optimization and characterization of exopolysaccharide produced by Bacillus aerophilus rk1 and its in vitro antioxidant activities. J. King Saud Univ. Sci. 33:101470.

Haroun-Bouhedja, F., Ellouali, M., Sinquin, C., and Boisson-Vidal, C. (2000). Relationship between sulfate groups and biological activities of fucans. Thromb. Res. 100, 453-459. doi: 10.1016/s0049-3848(00)00338-8

Hu, X., Pang, X., Wang, P. G., and Chen, M. (2019). Isolation and characterization of an antioxidant exopolysaccharide produced by Bacillus sp. S-1 from Sichuan pickles. Carbohydr. Polym. 204, 9-16. doi: 10.1016/j.carbpol.2018.09.069

Insulkar, P., Kerkar, S., and Lele, S. (2018). Purification and structural-functional characterization of an exopolysaccharide from Bacillus licheniformis PASS26 with in-vitro antitumor and wound healing activities. Int. J. Biol. Macromol. 120, 1441-1450. doi: 10.1016/j.ijbiomac.2018.09.147

Karadayi, Y. I., Aykutoglu, G., Arslan, N. P., Baltaci, M. O., Adiguzel, A., Taskin, M., et al. (2021). Production of water-soluble sulfated exopolysaccharide with anticancer activity from Anoxybacillus gonensis YK25. J. Chem. Technol. 96, 1258-1266. doi: $10.1002 /$ jctb.6638

Kasibhatla, S., Amarante-Mendes, G. P., Finucane, D., Brunner, T., Bossy-Wetzel, E., and Green, D. R. (2006). Acridine orange/ethidium bromide (AO/EB) staining to detect apoptosis. Cold Spring Harb. Protoc. 2006:pdb.prot4493. doi: 10.1101/pdb.prot4493

Krishnamurthy, M., Uthaya, C. J., Thangavel, M., Annadurai, V., Rajendran, R., and Gurusamy, A. (2020). Optimization, compositional analysis, and characterization of exopolysaccharides produced by multi-metal resistant Bacillus cereus KMS3-1. Carbohydr. Polym. 227:115369. doi: 10.1016/j.carbpol. 2019.115369

Kumar Bajaj, B., Razdan, K., Jj Claes, I., and Lebeer, S. (2015). Physico-chemical characterization of exopolysaccharides of potential probiotic Enterococcus faecium isolates from infants' gut. Curr. Biochem. Eng. 2, 90-100. doi: 10.2174/ 2212711901666140813195303

Li, W., Xia, X., Tang, W., Ji, J., Rui, X., Chen, X., et al. (2015). Structural characterization and anticancer activity of cell-bound exopolysaccharide from Lactobacillus helveticus MB2-1. J. Agric. Food Chem. 63, 3454-3463. doi: 10. 1021/acs.jafc.5b01086

Liu, J., Luo, J., Ye, H., Sun, Y., Lu, Z., and Zeng, X. (2010). In vitro and in vivo antioxidant activity of exopolysaccharides from endophytic bacterium Paenibacillus polymyxa EJS-3. Carbohydr. Polym. 82, 1278-1283.

Lynch, K. M., Zannini, E., Coffey, A., and Arendt, E. K. (2018). Lactic acid bacteria exopolysaccharides in foods and beverages: isolation, properties, characterization, and health benefits. Annu. Rev. Food Sci. Technol. 9, 155-176. doi: 10.1146/annurev-food-030117-012537

Ma, W., Chen, X., Wang, B., Lou, W., Chen, X., Hua, J., et al. (2018). Characterization, antioxidativity, and anti-carcinoma activity of exopolysaccharide extract from Rhodotorula mucilaginosa CICC 33013. Carbohydr. Polym. 181, 768-777. doi: 10.1016/j.carbpol.2017.11.080

Mathivanan, K., Chandirika, J. U., Vinothkanna, A., Govindarajan, R., Meng, D., and Yin, H. (2021). Characterization and biotechnological functional activities of exopolysaccharides produced by Lysinibacillus fusiformis KMNTT10. J. Polym. Environ. 29, 1742-1751.

Mohamed, S. S., Amer, S. K., Selim, M. S., and Rifaat, H. M. (2018). Characterization and applications of exopolysaccharide produced by marine Bacillus altitudinis MSH2014 from Ras Mohamed, Sinai, Egypt. Egypt. J. Basic Appl. Sci. 5, 204-209. doi: 10.1016/j.ejbas.2018.05.009

Noseda, M. D., Bonatto, S. J., de Freitas, R. A., de Carvalho, J. C., and Soccol, C. R. (2020). Production, characterization, and biological activity of a chitin-like EPS produced by Mortierella alpina under submerged fermentation. Carbohydr. Polym. 247:116716. doi: 10.1016/j.carbpol.2020.116716

Nouha, K., Kumar, R. S., Balasubramanian, S., and Tyagi, R. D. (2018). Critical review of EPS production, synthesis and composition for sludge flocculation. J. Environ. Sci. 66, 225-245. doi: 10.1016/j.jes.2017.05.020

Nwodo, U. U., Green, E., and Okoh, A. I. (2012). Bacterial exopolysaccharides: functionality and prospects. Int. J. Mol. Sci. 13, 14002-14015. doi: 10.3390/ ijms 131114002

Okaiyeto, K., Nwodo, U. U., Okoli, S. A., Mabinya, L. V., and Okoh, A. I. (2016). Implications for public health demands alternatives to inorganic and synthetic flocculants: bioflocculants as important candidates. Microbiol. Open 5, 177-211. doi: $10.1002 / \mathrm{mbo} 3.334$
Park, S., Saravanakumar, K., Sathiyaseelan, A., Park, S., Hu, X., and Wang, M.-H. (2022). Cellular antioxidant properties of nontoxic exopolysaccharide extracted from Lactobacillales (Weissella cibaria) isolated from Korean kimchi. LWT 154:112727.

Pei, F., Ma, Y., Chen, X., and Liu, H. (2020). Purification and structural characterization and antioxidant activity of levan from Bacillus megaterium PFY-147. Int. J. Biol. Macromol. 161, 1181-1188. doi: 10.1016/j.ijbiomac.2020. 06.140

Ramamoorthy, S., Gnanakan, A., Lakshmana, S. S., Meivelu, M., and Jeganathan, A. (2018). Structural characterization and anticancer activity of extracellular polysaccharides from ascidian symbiotic bacterium Bacillus thuringiensis. Carbohydr. Polym. 190, 113-120. doi: 10.1016/j.carbpol.2018.02.047

Rani, R. P., Anandharaj, M., Sabhapathy, P., and Ravindran, A. D. (2017). Physiochemical and biological characterization of novel exopolysaccharide produced by Bacillus tequilensis FR9 isolated from chicken. Int. J. Biol. Macromol. 96, 1-10. doi: 10.1016/j.ijbiomac.2016.11.122

Ruiz-Ruiz, C., Srivastava, G. K., Carranza, D., Mata, J. A., Llamas, I., Santamaría, M., et al. (2011). An exopolysaccharide produced by the novel halophilic bacterium Halomonas stenophila strain B100 selectively induces apoptosis in human T leukaemia cells. Appl. Microbiol. Biotechnol. 89, 345-355. doi: 10.1007/ s00253-010-2886-7

Saadat, Y. R., Khosroushahi, A. Y., and Gargari, B. P. (2019). A comprehensive review of anticancer, immunomodulatory and health beneficial effects of the lactic acid bacteria exopolysaccharides. Carbohydr. Polym. 217, 79-89. doi: 10.1016/j.carbpol.2019.04.025

Saravanakumar, K., Park, S., Sathiyaseelan, A., Mariadoss, A. V. A., Park, S., Kim, S.-J., et al. (2021). Isolation of polysaccharides from Trichoderma harzianum with antioxidant, anticancer, and enzyme inhibition properties. Antioxidants 10:1372. doi: 10.3390/antiox 10091372

Sardari, R. R. R., Kulcinskaja, E., Ron, E. Y. C., Björnsdóttir, S., Friðjónsson, Ó. H., and Hreggviðsson, G. Ó. (2017). Evaluation of the production of exopolysaccharides by two strains of the thermophilic bacterium Rhodothermus marinus. Carbohydr. Polym. 156, 1-8. doi: 10.1016/j.carbpol.2016.08.062

Sathishkumar, R., Kannan, R., Jinendiran, S., Sivakumar, N., Selvakumar, G., and Shyamkumar, R. (2021). Production and characterization of exopolysaccharide from the sponge-associated Bacillus subtilis MKU SERB2 and its in-vitro biological properties. Int. J. Biol. Macromol. 166, 1471-1479. doi: 10.1016/j. ijbiomac.2020.11.026

Sathiyanarayanan, G., Bhatia, S. K., Kim, H. J., Kim, J.-H., Jeon, J.-M., Kim, Y.-G., et al. (2016). Metal removal and reduction potential of an exopolysaccharide produced by Arctic psychrotrophic bacterium Pseudomonas sp. PAMC 28620. RSC Adv. 6, 96870-96881. doi: 10.1039/c6ra17450g

Sathiyanarayanan, G., Vignesh, V., Saibaba, G., Vinothkanna, A., Dineshkumar, K., Viswanathan, M. B., et al. (2014). Synthesis of carbohydrate polymer encrusted gold nanoparticles using bacterial exopolysaccharide: a novel and greener approach. RSC Adv. 4, 22817-22827. doi: 10.1039/c4ra01428f

Sekar, S., and Vinothkanna, A. (2019). Polyherbal and submerge fermented medicines of Ayurveda: convergence of tradition with scientific trends and needs. S. Afr. J. Bot. 121, 410-417.

Sivasankar, P., Seedevi, P., Poongodi, S., Sivakumar, M., Murugan, T., Sivakumar, L., et al. (2018). Characterization, antimicrobial and antioxidant property of exopolysaccharide mediated silver nanoparticles synthesized by Streptomyces violaceus MM72. Carbohydr. Polym. 181, 752-759. doi: 10.1016/j.carbpol.2017. 11.082

Sun, M.-L., Zhao, F., Shi, M., Zhang, X.-Y., Zhou, B.-C., Zhang, Y.-Z., et al. (2015). Characterization and biotechnological potential analysis of a new exopolysaccharide from the Arctic marine bacterium Polaribacter sp. SM1127. Sci. Rep. 5:18435. doi: 10.1038/srep18435

Sun, X., Wang, L., Fu, R., Yang, Y., Cheng, R., Li, J., et al. (2020). The chemical properties and hygroscopic activity of the exopolysaccharide lubcan from Paenibacillus sp. ZX1905. Int. J. Biol. Macromol. 164, 2641-2650. doi: 10.1016/ j.ijbiomac.2020.08.129

Terho, T. T., and Hartiala, K. (1971). Method for determination of the sulfate content of glycosaminoglycans. Anal. Biochem. 41, 471-476. doi: 10.1016/00032697(71)90167-9

Vijayabaskar, P., Babinastarlin, S., Shankar, T., and Sivakumar, T. (2011). Quantification and characterization of exopolysaccharides from Bacillus subtilis (MTCC 121). Adv. Biol. Res. 5, 71-76. 
Vinothkanna, A., Sathiyanarayanan, G., Balaji, P., Mathivanan, K., Pugazhendhi, A., Ma, Y., et al. (2021). Structural characterization, functional and biological activities of an exopolysaccharide produced by probiotic Bacillus licheniformis AG-06 from Indian polyherbal fermented traditional medicine. Int. J. Biol. Macromol. 174, 144-152. doi: 10.1016/j.ijbiomac.2021.01.117

Vinothkanna, A., and Sekar, S. (2019). Probiotic properties of intrinsic bacteria isolated from fermented polyherbal preparations of Indian Ayurveda. LWT Food Sci. Technol. 103, 8-18. doi: 10.1016/j.lwt.2018.12.068

Wang, J., Zhao, X., Tian, Z., Yang, Y., and Yang, Z. (2015). Characterization of an exopolysaccharide produced by Lactobacillus plantarum YW11 isolated from Tibet Kefir. Carbohydr. Polym. 125, 16-25. doi: 10.1016/j.carbpol.2015.03.003

Wang, L., Wang, Y., Li, Q., Tian, K., Xu, L., Liu, G., et al. (2019). Exopolysaccharide, isolated from a novel strain Bifidobacterium breve lw01 possess an anticancer effect on head and neck cancer-genetic and biochemical evidences. Front. Microbiol. 10:1044. doi: 10.3389/fmicb.2019.01044

$\mathrm{Xu}, \mathrm{R}$., Shang, N., and Li, P. (2011). In vitro and in vivo antioxidant activity of exopolysaccharide fractions from Bifidobacterium animalis RH. Anaerobe 17, 226-231.

Xu, Z., Chen, G., Xue, L., Zhang, H., Wang, J., Xiang, H., et al. (2019). Isolation, structural characterizations and bioactivities of exopolysaccharides produced by Bacillus licheniformis. Int. J. Biol. Macromol. 141, 298-306. doi: 10.1016/j. ijbiomac.2019.08.217

You, X., Li, Z., Ma, K., Zhang, C., Chen, X., Wang, G., et al. (2020). Structural characterization and immunomodulatory activity of an exopolysaccharide produced by Lactobacillus helveticus LZ-R-5. Carbohydr. Polym. 235:115977. doi: 10.1016/j.carbpol.2020.115977
Zhao, W., Zhang, J., Jiang, Y.-Y., Zhao, X., Hao, X.-N., Li, L., et al. (2018). Characterization and antioxidant activity of the exopolysaccharide produced by Bacillus amyloliquefaciens GSBa-1. J. Microbiol. Biotechnol. 28, 1282-1292. doi: 10.4014/jmb.1801.01012

Zhou, K., Zeng, Y., Yang, M., Chen, S., He, L., Ao, X., et al. (2016). Production, purification and structural study of an exopolysaccharide from Lactobacillus plantarum BC-25. Carbohydr. Polym. 144, 205-214. doi: 10.1016/j.carbpol. 2016.02.067

Conflict of Interest: The authors declare that the research was conducted in the absence of any commercial or financial relationships that could be construed as a potential conflict of interest.

Publisher's Note: All claims expressed in this article are solely those of the authors and do not necessarily represent those of their affiliated organizations, or those of the publisher, the editors and the reviewers. Any product that may be evaluated in this article, or claim that may be made by its manufacturer, is not guaranteed or endorsed by the publisher.

Copyright (C) 2022 Vinothkanna, Sathiyanarayanan, Rai, Mathivanan, Saravanan, Sudharsan, Kalimuthu, Ma and Sekar. This is an open-access article distributed under the terms of the Creative Commons Attribution License (CC BY). The use, distribution or reproduction in other forums is permitted, provided the original author(s) and the copyright owner(s) are credited and that the original publication in this journal is cited, in accordance with accepted academic practice. No use, distribution or reproduction is permitted which does not comply with these terms. 